\title{
Nâng cao hiệu quả hoạt động hợp tác quốc tế của đại học Việt Nam trong bối cảnh cộng đồng ASEAN, tầm nhìn 2025 (Nghiên cứu trường hợp ĐHQG-HCM, giai đoạn 2021 - 2025)
}

\section{Enhancing the efficiency of international cooperation's operation of Vietnam's universities in the context of the ASEAN community, vision 2025 (Case study of VNU-HCM, period 2021 - 2025)}

\author{
Phan Thị Hồng Xuân ${ }^{1 *}$ \\ ${ }^{1}$ Trường Đại học Khoa học Xã Hội và Nhân văn, ĐHQG Thành phố Hồ Chí Minh, Việt Nam \\ *Tác giả liên hệ, Email: phanhxuan@yahoo.com
}

THÔNG TIN

DOI: $10.46223 / \mathrm{HCMCOUJS}$. soci.vi.16.1.1778.2021

Ngày nhận: 29/03/2021

Ngày nhận lại: 20/04/2021

Duyệt đăng: 27/04/2021

Tù khóa:

nâng cao, hiệu quả, hợp tác quốc tế, ĐHQG-HCM

Keywords:

enhancement, efficiency, international cooperation, VNU-HCM

\section{TÓM TẮT}

ĐHQG-HCM với lịch sử hình thành và phát triển hơn 25 năm đạt được nhiều thành tựu nổi bật, xứng đáng là một mô hình kiểu mẫu cho đô thị đại học và hệ thống các trường đại học Việt Nam tham khảo. Một trong những dấu ấn quan trọng phản ánh một diện mạo mới, sức sống mới của hệ thống ĐHQG-HCM đó là hoạt động hợp tác quốc tế, chủ động hội nhập vào xu hướng phát triển của hệ thống giáo dục đại học ASEAN. Để nâng cao hiệu quả hoạt động hợp tác quốc tế của ĐHQG-HCM giai đoạn 2021 - 2025, tác giả bài viết đã điểm luận lại năm mục tiêu phát triển giáo dục và tầm quan trọng của hợp tác giáo dục Việt Nam trong ASEAN; từ đó đề xuất một số ý kiến để khai thác tối đa tiềm năng của hợp tác quốc tế trong ASEAN góp phần nâng cao vị thế quốc tế của ĐHQG-HCM trong thời gian tới.

\section{ABSTRACT}

VNU-HCM, with a history of over 25 years of establishment and development, has achieved many outstanding achievements, deserving to be a model for the urban university. One of the important stamp reflecting a new and vibrant face of the system of VNU-HCM is international cooperation, proactive in the development trend of the ASEAN higher education system. To improve the efficiency of international cooperation activities of VNU-HCM in the period of 2021 - 2025, the author has reviewed five educational development goals and the importance of educational cooperation of Vietnam in ASEAN; from there, proposing a number of ideas to maximize the potential for international cooperation among ASEAN's universities to contribute enhancing the international position of VNU-HCM in the coming time. 


\section{Dẫn nhập}

Cộng đồng Văn hóa - Xã hội ASEAN (ASCC) là một trong ba trụ cột của Cộng đồng ASEAN, với mục tiêu xây dựng một cộng đồng các dân tộc ASEAN hài hòa, đoàn kết, sống đùm bọc và chia sẻ, hướng tới người dân, chăm lo cho thể chất, phúc lợi, môi trường sống ngày càng tốt hơn của người dân, và tạo dựng một bản sắc chung của khu vực.

Các lĩnh vực hoạt động của ASCC hết sức đa dạng như giáo dục, y tế, lao động, phúc lợi xã hội, phát triển nông thôn và xóa đói giảm nghèo, trao quyền, bảo vệ và thúc đẩy quyền của phụ nữ và trẻ em, văn hóa và nghệ thuật, thông tin, thể thao, môi trường, ô nhiễm khói mù xuyên biên giới, dịch vụ dân sự và quản lý thiên tai cũng như hỗ trợ nhân đạo.

Trên lĩnh vực giáo dục: sự quan tâm của $\mathrm{ASCC}$ hướng tới mục tiêu phát triển bền vững là cơ hội và triển vọng rất lớn cho các trường đại học Việt Nam nói chung, Đại học Quốc gia - HCM nói riêng tăng cường mối quan hệ hợp tác với các trường đại học, các Viện nghiên cứu, các tổ chức văn hóa - giáo dục ASEAN cũng như thế giới, hiện thực hóa triết lý đại học: chuyển những giá trị tinh thần, khoa học thành giá trị hiện thực của kinh tế - xã hội.

Vào năm 2021, theo kế hoạch ĐHQG-HCM sẽ đăng cai tổ chức hội nghị AUN về đảm bảo chất lượng. Đây là lần đầu tiên hội nghị này được tổ chức tại Việt Nam, quy tụ các chuyên gia hàng đầu về công tác đảm bảo, kiểm định chất lượng nhằm nâng cao sự tin tưởng lẫn nhau về chất lượng đào tạo giữa các trường trong khu vực $\mathrm{ASEAN}$ cũng như các trường đại học đối tác trên thế giới (ĐHQG-HCM, 2020).

Để nâng cao hơn nữa hiệu quả hoạt động hợp tác quốc tế của ĐHQG-HCM (giai đoạn 2021 - 2025), từ lý luận của Chủ nghĩa kiến tạo trong hợp tác quốc tế, chúng tôi khẳng định việc hợp tác giáo dục giữa ĐHQG-HCM với các trường, đối tác trong ASEAN sẽ "phục vụ và nâng cao chất lượng cuộc sống của người dân ASEAN, tập trung xử lý các vấn đề liên quan tới bình đẳng và công bằng xã hội, bản sắc văn hóa, môi trường, tác động của toàn cầu hóa và khoa học công nghệ." (Pham, 2008).

\section{trong ASEAN \\ 1. Mục tiêu phát triển giáo dục và tầm quan trọng của hợp tác giáo dục Việt Nam}

Để có cơ sở xác định ý nghĩa và tầm quan trọng của hợp tác giáo dục trong ASEAN, chúng tôi xin được điểm lại mục tiêu phát triển giáo dục trong cộng đồng chung ASEAN, đó là: (1) Phát triển khung tham chiếu kỹ năng của từng quốc gia và hướng tới khung tham chiếu kỹ năng của khu vực ASEAN; (2) Thúc đẩy sự dịch chuyển ngày càng dễ dàng hơn giữa sinh viên của các nước; (3) Hỗ trợ sự di chuyển của những người lao động có kỹ năng tốt thông qua các sự hợp tác giữa các quốc gia và nỗ lực tạo dựng những tiêu chuẩn chuyên nghiệp về giáo dục; (4) Phát triển chuẩn nghề nghiệp dựa trên năng lực của cộng đồng ASEAN; (5) Khuyến khích sự phát triển của các chuẩn chung về năng lực để thúc đẩy sự hội nhập giữa các quốc gia (Dinh, n.d.).

Mặc dù ASEAN đề ra những mục tiêu phát triển giáo dục trong nội khối tương đối rõ ràng từ năm 2015 nhưng kết quả đạt được về hợp tác giáo dục giữa các trường đại học ASEAN còn khá khiêm tốn, trong đó có một số nguyên nhân: Sự chênh lệch về trình độ giáo dục giữa các nước ASEAN vẫn còn khá lớn (về chất lượng giáo dục, trình độ quản lý giáo dục, nguồn tài chính cho giáo dục, tiêu chuẩn tuyển sinh đầu vào các cấp học; khoảng cách trong phát triển giữa đô thị và nông thôn...); Sự hợp tác giữa các tổ chức giáo dục trong ASEAN chưa chặt chẽ, đồng bộ (chẳng hạn như $\mathrm{AUN}$ và SEAMEO...); Ngoài ra, có thách thức không nhỏ trong việc công nhận bằng cấp của nhau giữa các trường đại học trong khu vực, trong tiến trình hiện thực hóa mục tiêu cộng đồng ASEAN lĩnh vực giáo dục đại học. 
Do nhiều yếu tố khách quan của lịch sử tác động dẫn đến nền giáo dục Việt Nam có nhiều khác biệt và khoảng cách so với các nước ASEAN 6 (Indonesia, Malaysia, Singapore, Thailand, Singapore, Brunei). Trong tiến trình hội nhập quốc tế, Việt Nam xem cải cách giáo dục là một yêu cầu tất yếu để hội nhập tích cực trong ASEAN, nâng cao chất lượng đào tạo phục vụ $\mathrm{CNH}$ - $\mathrm{HĐH}$ đất nước. Xét ở tầm vĩ mô, đối với giáo dục Việt Nam, việc tham khảo khung tham chiếu trình độ của các nước tiên tiến để xây dựng khung tham chiếu chuẩn trình độ quốc gia, và hướng đến đạt chuẩn theo yêu cầu khung tham chiếu trình độ ASEAN, là một nhiệm vụ thực sự cần thiết. Theo đó, mục tiêu giáo dục của các trường đại học, nhất là trường đại học quốc gia là phải đào tạo ra những công dân có kiến thức đa ngành, liên ngành, tư duy toàn diện, kỹ năng thích ứng với những biến đổi như vũ bão của khoa học kỹ thuật tác động đến kinh tế - xã hội toàn cầu; vừa thấm nhuần bản sắc dân tộc, vừa có tinh thần công dân toàn cầu. Trong đó, kĩ năng sử dụng thành thạo tiếng Anh được xem là kỹ năng thiết yếu, phổ biến mà mọi người học phải được trang bị để vận dụng trong học thuật và làm việc...

Nhờ có sự hợp tác phát triển giáo dục trong ASEAN, Việt Nam đã có nhiều cơ hội nâng cao chất lượng nguồn nhân lực, đáp ứng cho lực lượng lao động có tay nghề cao thực hiện $\mathrm{CNH}$ HĐH đất nước, tham gia thị trường lao động quốc tế. Có thể nói giáo dục - lao động - việc làm là chuỗi mắt xích gắn kết với nhau và mang ý nghĩa quan trọng trong việc ổn định và phát triển đất nước. Các sự kiện hợp tác giáo dục giữa ASEAN với Việt Nam trong hơn một thập kỷ qua có thể kể đến như Diễn đàn Giáo dục ASEAN năm 2007 tại Hà Nội nhằm mục đích để các nước trong khu vực cùng nhau trao đổi kinh nghiệm, thảo luận những nội dung, hình thức hợp tác, hội nhập, tìm ra những giải pháp để đưa giáo dục ASEAN lên tầm cao mới; Hội nghị Bộ trưởng Giáo dục các nước Đông Nam Á được tổ chức vào ngày 11/09/2014 tại Vientiane, Lào đã đưa ra kết quả đánh giá khả quan trong việc kết nối nguồn nhân lực, công nghệ thông tin và dạy tiếng Anh, giúp thu hẹp khoảng cách chênh lệch về phát triển trong khu vực; nhất trí về nhu cầu mở rộng hoạt động hợp tác giáo dục ra các nước CLMV (Campuchia, Lào, Myanmar và Việt Nam) và tăng cường cơ chế “ASEAN giúp ASEAN" nhằm hỗ trợ các quốc gia đang phát triển trong ASEAN. Trên cơ sở đó, Khung Tham chiếu Trình độ ASEAN (AQRF) đã được các bộ trưởng ASEAN phê duyệt làm tài liệu hướng dẫn cho các quốc gia thành viên ASEAN, hướng đến thực hiện tầm nhìn của Cộng đồng ASEAN 2015. Cá nhân tôi cũng đã được tham dự khóa tập huấn về kỹ năng giảng dạy (dành cho đối tượng là giảng viên các nước kết nạp sau trong ASEAN: Việt Nam, Lào, Campuchia, Myanmar) vào năm 2003. Đây là chương trình ký kết hợp tác giữa Bộ ngoại giao Singapore, Bộ Giáo dục Singapore với Bộ Giáo dục và Đào tạo của Việt Nam.

Với mục tiêu phát triển nguồn nhân lực thông qua giáo dục đại học khu vực ASEAN, năm 1995 Mạng lưới các trường Đại học khu vực Đông Nam Á (ASEAN University Network) đã được thành lập. Nhằm đẩy mạnh công tác đảm bảo chất lượng bên trong các trường đại học trong khu vực, AUN đã đưa ra sáng kiến đánh giá chất lượng chung của khu vực ASEAN (ASEAN University Network - Quality Assurance, viết tắt là AUN-QA). Theo thống kê của Bộ Giáo dục và Đào tạo, quy mô đào tạo bậc đại học của Việt Nam tăng mạnh theo từng năm học. Từ năm học 2008 - 2009, quy mô đào tạo bậc đại học tăng từ 12-13\%. Từ năm 2010 đến nay, quy mô đào tạo bậc đại học tăng từ 6-6.5\% theo từng năm giảm hơn trước năm 2009 khoảng 6\%, nhưng đây vẫn là tốc độ tăng mạnh về số lượng. Việc lựa chọn tiêu chuẩn AUN-QA của nhiều trường Đại học tại Việt Nam để làm chuẩn mực hướng tới không chỉ đem lại lợi ích cho nhà trường, sinh viên mà cả người sử dụng lao động. Theo đó, sinh viên sẽ được đảm bảo học tập trong môi trường được cải tiến liên tục và đảm bảo chất lượng. Về chương trình đào tạo, ĐHQG-HCM hiện dẫn đầu cả nước với 66 chương trình đạt chuẩn khu vực và quốc tế (chiếm gần $50 \%$ số lượng của cả nước). Trong đó có 53 chương trình đạt chuẩn AUN-QA. Năm 2021, ĐHQG-HCM đăng cai tổ chức hội nghị AUN về đảm bảo chất lượng. Việc các trường đại học Việt Nam, cụ thể là các trường thành viên 
của Đại học Quốc gia - HCM tham gia xếp hạng AUN - QA mang lại nhiều ý nghĩa quan trọng khẳng định chuẩn $\mathrm{ASEAN}$ về chất lượng đào tạo đại học Việt Nam; giúp các trường và toàn hệ thống giáo dục luôn đổi mới, cải tiến, nâng cao chất lượng đào tạo; thu hút các nhà khoa học, các giảng viên quốc tế tham gia vào quá trình giảng dạy đại học trên nền tảng tiếng Anh - ngôn ngữ hội thoại quốc tế và chia sẻ học thuật; thu hút sinh viên quốc tế học tập, tham gia thị trường lao động chất lượng cao ở các đô thị, thành phố lớn ở Việt Nam; góp phần thực hiện mục tiêu chiến lược quan trọng của địa phương; tăng lượng khách du lịch, tăng GDP cho thành phố, phát triển kinh tế tri thức.

\section{Một số ý kiến nâng cao hơn nữa hiệu quả hoạt động hợp tác quốc tế giữa ĐHQG- HCM với các trường thành viên ASEAN (giai đoạn 2021 - 2025)}

Để hoạt động hợp tác quốc tế giữa ĐHQG-HCM với các trường thành viên ASEAN (giai đoạn 2021 - 2025) mang lại nhiều hiệu quả thiết thực, chúng tôi xin góp thêm một số ý kiến cụ thể như sau:

2.1. Ban Đối ngoại và Phát triển Dự án - ĐHQG-HCM và các trường thành viên trong hệ thống ĐHQG cần bám sát năm mục tiêu hợp tác giáo dục ASEAN như bên trên chúng tôi đã đề cập.

- Với mục tiêu (1) Phát triển khung tham chiếu kỹ năng của từng quốc gia và hướng tới khung tham chiếu kỹ năng của khu vực ASEAN: bên cạnh kiểm định AUN-QA, các trường cần chủ động dựa trên tám nhóm ngành được công nhận tay nghề tương đương di chuyển trong nội khối, đưa ra khung tham chiếu kỹ năng; mở các lớp đào tạo cấp chứng chỉ theo khung tham chiếu được công nhận liên các trường đại học $\mathrm{ASEAN}$; giữa ĐHQG-HCM với một trường đại học quốc gia trong ASEAN như NUS, UP, ...

- Với mục tiêu (2) Thúc đẩy sự dịch chuyển ngày càng thuận lợi hơn giữa sinh viên của các nước ASEAN: cần tăng cường các hoạt động giao lưu văn hóa; trao đổi sinh viên giữa ĐHQG$\mathrm{HCM}$ với các trường đại học $\mathrm{ASEAN}$ thông qua nhiều hình thức linh hoạt, công nhận tín chỉ các môn học tương đương được giảng dạy bằng tiếng Anh của ĐHQG-HCM; tổ chức các lớp hè, nghiên cứu thực địa,...

- Với mục tiêu (3) Hỗ trợ sự di chuyển đối với đối tượng người lao động có kỹ năng tốt thông qua các sự hợp tác giữa các quốc gia và nỗ lực tạo dựng những tiêu chuẩn chuyên nghiệp về giáo dục: ĐHQG-HCM có thể thành lập trung tâm / trang web giới thiệu việc làm, cung ứng lao động chất lượng cao đi làm việc, hợp tác nghiên cứu, giảng dạy ở ASEAN, ....

- Với mục tiêu (4) Phát triển chuẩn nghề nghiệp dựa trên năng lực của cộng đồng ASEAN: Tổ chức những cuộc thi chuyên môn/ tay nghề liên các trường ASEAN,... (Phan, 2020).

- Với mục tiêu (5) Khuyến khích sự phát triển của các chuẩn chung về năng lực để thúc đẩy sự hội nhập giữa các quốc gia: ĐHQG-HCM gồm có nhiều trường đại học thành viên với các ngành đào tạo đa dạng từ khoa học tự nhiên, $\mathrm{KHXH}$ và $\mathrm{NV}$, khoa học kỹ thuật, $\mathrm{y}$ sinh,... ; tám nhóm ngành được công nhận tay nghề tương đương, lao động có thể di chuyển làm việc trong nội khối đều là các ngành đang giảng dạy và có thế mạnh trong các trường thành viên của ĐHQG$\mathrm{HCM}$, có nhiều ngành đã được kiểm định AUN-QA, đây là cơ sở thuận lợi để ĐHQG-HCM có thể chủ động đưa ra các chuẩn chung về năng lực ASEAN, thúc đẩy tiến trình hội nhập giữa các quốc gia nội khối. Ngoài ra, cần xuất khẩu một số chương trình đào tạo chất lượng cao ra thị trường ASEAN, ví như: y khoa, trí tuệ nhân tạo, Việt Nam học, Đông Nam Á học,...

2.2. Tổ chức hội thảo gắn với mục tiêu phát triển ASEAN tầm nhìn đến năm ASEAN. Đơn cử: Hội thảo về mạng lưới các thành phố thông minh trong ASEAN; Đô thị phát triển bền vững; Trí tuệ nhân tạo; Văn hóa, văn minh ASEAN; Khởi nghiệp sáng tạo ASEAN, Cách mạng công nghiệp 4.0; Kinh tế tri thức, ... 
2.3. Tổ chức Hội thảo liên trường đại học ASEAN trong các lĩnh vực như quản lý giáo dục đại học; giáo dục sáng tạo; giáo dục đa văn hóa, công nghệ giáo dục...

2.4. Tổ chức trại hè $\mathrm{ASEAN}$ summer camp cho giảng viên và sinh viên các trường đại học ASEAN tham gia khám phá văn hóa ASEAN (các trường thành viên đăng cai tổ chức mỗi năm 1 lần).

2.5. Hợp tác nghiên cứu, công bố quốc tế trên tạp chí, xuất bản sách có chỉ số ISBN quốc tế.

2.6. Tổ chức các lớp ngắn hạn đào tạo kỹ năng, phương pháp nghiên cứu thực địa phục vụ cộng đồng, ... cho giảng viên và sinh viên các trường đại học ASEAN, ...

2.7. Thành lập góc Văn hóa ASEAN trong khuôn viên trường hoặc nếu không có nhiều diện tích dành cho không gian công cộng, góc văn hóa ASEAN có thể được đặt tại thư viện trường với quốc kỳ, quốc hoa các nước ASEAN, logo ASEAN, sách nghiên cứu về ASEAN. Hàng năm tổ chức Lễ hội giao lưu văn hóa giáo dục ASEAN, mời các tổng lãnh sự quốc gia đang giữ vai trò chủ tịch luân phiên ASEAN đến phát biểu chúc mừng sự kiện.

\section{Kết luận}

Với vị thế của đại học đa ngành, đa lĩnh vực, là mô hình đô thị đại học kiểu mẫu ở Việt Nam, ĐHQG-HCM đã được các đối tác quốc tế quan tâm từ rất sớm, đặc biệt là các trường đại học ASEAN. Ngay từ những ngày đầu thành lập, ĐHQG-HCM đã tăng cường hợp tác quốc tế trong đào tạo và NCKH, đẩy mạnh công tác kiểm định. Từ năm 2007, ĐHQG-HCM đã bắt đầu thực hiện triển khai đào tạo theo tiếp cận đầu ra (Outcomes Based Education) đúng với định hướng chung của mạng lưới các trường đại học ASEAN (AUN). Chuẩn đầu ra của các chương trình đào tạo được rà soát và hoàn chỉnh căn cứ trên yêu cầu thực tế của các bên liên quan. Các hoạt động dạy/học/đánh giá được thiết kế một cách có hệ thống giúp người học đạt được chuẩn đầu ra của chương trình, theo đó chất lượng các chương trình đào tạo tại ĐHQG-HCM đã có những bước tiến bộ đáng kể.

Trong thời gian tới (giai đoạn 2021 - 2025), theo ý kiến của chúng tôi, ĐHQG-HCM cần bám sát 5 mục tiêu hợp tác giáo dục ASEAN để phát huy hơn nữa thế mạnh và tiềm năng của toàn hệ thống, cung cấp nguồn nguồn nhân lực cho các địa phương thực hiện $\mathrm{CNH}-\mathrm{H} Đ H$ trên nền tảng kinh tế tri thức và kinh tế tuần hoàn.

\section{Tài liệu tham khảo}

Dinh, N. T. T. (n.d.). Tọa đàm "Tính cấp thiết cải cách giáo dục trong quá trình hội nhập ASEAN" [Seminar "The urgency of educational reform in ASEAN integration"]. Retrieved March 17, 2021, from http://edufac.edu.vn/toa-dam-tinh-cap-thiet-cai-cach-giao-duc-trong-quatrinh-hoi-nhap-asean

Đại học Quốc gia Thành phố Hồ Chí Minh (ĐHQG-HCM). (2020). ĐHQG-HCM: 25 năm phát triển toàn diện [VNU-HCM: 25 years of comprehensive development]. Retrieved March 17, 2021, from Đại học Quốc Gia TP. Hồ Chí Minh website: https://vnuhcm.edu.vn/nghiencuu_33366864/dhqg-hcm-25-nam-phat-trien-toan-dien/323536306864.html

Pham, K. G. (2008). ASEAN bước vào giai đoạn phát triển mói [Asean enters a new stage of development]. Retrieved March 18, 2021, from https://nhandan.com.vn/tin-tuc-sukien/asean-buoc-vao-giai-doan-phat-trien-moi-586453

Phan, X. T. H. (2020). Quá trình hội nhập và phát triển của Việt Nam trong ASEAN [Vietnam's integration and development in ASEAN]. Nhịp cầu Hũu nghị - Liên hiệp các tổ chức hưu nghi TP.HCM, 25, 29-32. 